\title{
PENENTUAN PORTOFOLIO DAN VALUE AT RISK MENGGUNAKAN MODEL ARMA-GARCH
}

\author{
ADELLARA MUTYA R, MAIYASTRI, YUDIANTRI ASDI \\ Program Studi Matematika, \\ Fakultas Matematika dan Ilmu Pengetahuan Alam, Universitas Andalas, \\ Kampus UNAND Limau Manis Padang, Indonesia. \\ email : adellaramutya123@gmail.com
}

Diterima 9 Maret 2019 Direvisi 7 April 2019 Dipublikasikan 7 Mei 2019

\begin{abstract}
Abstrak. Dalam dunia investasi saham merupakan bentuk yang paling populer di kalangan masyarakat. Pada saham terdapat nilai risiko dan nilai ekspektasi return yang perlu dipertimbangkan oleh investor. Nilai Ekspektasi return dapat dihitung menggunakan model analisis deret waktu yaitu ARMA, sedangkan nilai risiko dapat diukur menggunakan beberapa metode salah satunya adalah metode Value at Risk (VaR). Untuk menghitung VaR diperlukan komponen volatilitas. Volatilitas dapat diestimasi menggunakan analisis deret waktu yaitu GARCH. Pada penelitian ini, peramalan dilakukan menggunakan data harga penutupan saham PT Astra Internasional Tbk, PT Bank Central Asia Tbk, PT Bank Negara Indonesia Tbk, PT Bank Rakyat Indonesia Tbk, dan PT Telekomunikasi Indonesia Tbk. Model terbaik yang didapatkan untuk mengestimasi nilai ekspektasi retrun diantaranya MA(1) untuk PT Astra Internasional Tbk, AR(1) untuk PT Bank Central Asia Tbk, ARMA(1,1) untuk PT Bank Rakyat Indonesia Tbk, MA(1) untuk PT Bank Rakyat Indonesia Tbk, dan MA(1) untuk PT Telekomunikasi Indonesia. Sedangkan model terbaik untuk mengestimasi nilai volatilitas adalah $\operatorname{GARCH}(1,1)$ untuk masing-masing perusahaan. Dengan menggunakan model ARMA-GARCH yang telah diestimasi diperoleh nilai VaR terbesar sampai terkecil secara berturut-turut terjadi pada saham PT Bank Negara Indonesia Tbk, PT Astra Internasional Tbk, PT Bank Rakyat Indonesia Tbk, PT Telekomunikasi Indonesia Tbk, dan PT Bank Central Asia Tbk. Bobot portofolio yang diperoleh adalah 5.47\% untuk saham PT Astra Internasional Tbk, $44.52 \%$ untuk saham PT Bank Central Asia Tbk, $1.49 \%$ untuk saham PT Bank Negara Indonesia Tbk, 6.48\% untuk saham PT Bank Rakyat Indonsia Tbk, dan $42.02 \%$ untuk saham PT Telekomunikasi Indonesia Tbk.
\end{abstract}

Kata Kunci: VaR, Portofolio, ARMA, GARCH

\section{Pendahuluan}

Setiap orang dihadapkan pada berbagai pilihan dalam menentukan proporsi dana atau sumber daya yang mereka miliki untuk konsumsi saat ini dan di masa datang. Begitu juga halnya dalam dunia bisnis, investasi merupakan suatu komitmen dengan menanamkan sejumlah dana pada saat ini dengan tujuan untuk memperoleh keuntungan di masa datang. Dalam investasi terdapat dua hal penting yang harus dipertimbangka investor yaitu nilai return dan nilai risiko. Untuk mengukur nilai risiko dapat menggunakan beberapa metode salah satunya metode Value at Risk (VaR). 
Untuk menghitung nilai risiko dengan metode VaR diperlukan suatu komponen yaitu volatilitas yang dapat diramalkan menggunakan model analisis deret waktu. Seorang investor yang rasional akan megharapkan nilai risiko yang rendah, karena itu salah satu konsep pengurangan risiko adalah portofolio [4]. Dalam tulisan ini akan dibahas mengenai bagaimana menentukan suatu portofolio dan menghitung nilai VaR dari nilai peramalan volatilitas menggunakan model ARMA-GARCH.

\section{Landasan Teori}

\subsection{Return dan Risiko}

Alasan utama seseorang berinvestasi adalah untuk memperoleh keuntungan. Dalam konteks manajemen investasi tingkat keuntungan investasi disebut sebagai return. Untuk menghitung tingkat pengembalian yang diharapkan dari saham individual dengan menggunakan rumus [4]:

$$
X_{t}=\frac{P_{t}-P_{t-1}}{P_{t-1}}
$$

Risiko bisa diartikan sebagai kemungkinan return aktual yang berbeda dengan return harapan. Pengukur variabilitas return yang paling umum digunakan adalah varian (variance) dan standar deviasi (standard deviation). Varian dihitung dengan rumus sebagai berikut [4]:

$$
\sigma^{2}=\frac{\Sigma\left(X_{t}-\bar{X}\right)^{2}}{n-1}
$$

\subsection{Model Moving Average-MA(q)}

Pada model Moving Average, nilai $X_{t}$ bergantung sisaan orde q sebelumnya. Moving Average orde q atau bisa disingkat $M A(q)$ memenuhi persamaan [5]:

$$
X_{t}=\varepsilon_{t}-\theta_{1} \varepsilon_{t-1}-\theta_{2} \varepsilon_{t-2}-\cdots-\theta_{q} \varepsilon_{t-q},
$$

dimana $\theta_{i}$ adalah koefisien moving average, $i=1,2, \cdots, q$.

\subsection{Model Autoregressive-AR(p)}

Proses autoregressive adalah model stasioner dari data deret waktu di mana nilai pengamatan waktu ke-t dipengaruhi oleh nilai pengamatan sebelumnya. Proses autoregressive $X_{t}$ orde ke-p disingkat $\mathrm{AR}(\mathrm{p})$ memenuhi persamaan sebagai berikut $[5]:$

$$
X_{t}=\phi_{1} X_{t-1}+\phi_{2} X_{t-2}+\cdots+\phi_{p} X_{t-p}+\varepsilon_{t},
$$

dimana $\phi_{i}$ adalah koefisien autoregressive, $i=1,2, \cdots, p$.

\subsection{Model Autoregressive Moving Average-ARMA(p,q)}

Jika diasumsikan deret waktu merupakan campuran dari autoregressive dan moving average maka model $\operatorname{ARMA}(\mathrm{p}, \mathrm{q})$ dapat ditulis sebagai berikut [5]:

$$
X_{t}=\phi_{1} X_{t-1}+\cdots+\phi_{p} X_{t-p}+\varepsilon_{t}-\theta_{1} \varepsilon_{t-1}-\cdots-\theta_{q} \varepsilon_{t-q} .
$$




\subsection{Volatilitas}

Volatilitas adalah ketidakpastian tentang hasil yang diperoleh dari data pada masa yang akan datang. Untuk mengukur besarnya volatilitas dilihat dari simpangan baku (standard deviation) return per satuan waktu [3].

\subsection{Generalized Autoregressive Conditional Heterocedasticity ( $\mathrm{GARCH}$ )}

Pada umumnya, pemodelan data deret waktu dilakukan dengan asumsi varian residual konstan (homokedastisitas). Pada kenyataannya, banyak data deret waktu yang mempunyai varian residual yang tidak konstan (heterokedastisitas), terutama pada data deret waktu bidang ekonomi. Pada kasus heterokedastisitas ini, model GARCH dapat menanganinya dengan baik. Secara umum, proses $\operatorname{GACH}(p, q)$ didefinisikan sebagai proses $\varepsilon_{t}$ yang memenuhi [5]:

$$
\begin{aligned}
X_{t} & =\phi_{1} X_{t-1}+\phi_{2} X_{t-2}+\cdots+\phi_{p} X_{t-p}+\varepsilon_{t}, \\
\sigma_{t}^{2} & =\alpha_{0}+\alpha_{1} \varepsilon_{t-1}^{2}+\cdots+\alpha_{q} \varepsilon_{t-q}^{2}+\beta_{1} \sigma_{t-1}^{2}+\cdots+\beta_{p} \sigma_{t-p}^{2},
\end{aligned}
$$

dengan $\varepsilon_{t}=\sigma_{t} e_{t}, \varepsilon_{t} \sim N(0,1), p \geq 0, q>0, \alpha_{0}>0, \alpha_{i} \geq 0, i=1,2, \cdots, q$ dan $\beta_{j} \geq 0$, untuk $j=1,2, \cdots, p$.

\subsection{Value at Risk (VaR)}

VaR merupakan sebuah konsep yang digunakan dalam pegukuran risiko dalam risk management. Secara sederhana VaR ingin menjawab pertanyaan seberapa besar (dalam persen atau sejumlah uang tertentu) investor dapat merugi selama waktu investasi T dengan tingkat kesalahan sebesar $\alpha$. Perhitungan VaR sebagai berikut $[3]:$

$$
\operatorname{VaR}=W_{0} Z_{\alpha} \widehat{\sigma} \sqrt{t}
$$

\subsection{Portofolio}

Portofolio digunakan untuk menyebutkan kumpulan investasi yang dimiliki oleh suatu perusahaan atau perorangan. Portofolio dimaksudkan sebagai strategi memaksimalkan tingkat keuntungan yang diharapkan dan meminimalkan risiko yang dihadapi. Perhitungan bobot portofolio adalah sebagai berikut [1]:

$$
\begin{aligned}
& w=\frac{(2 \tau+1) \Sigma^{-1} \mu+\lambda \Sigma^{-1} e}{(2 \tau+1) e^{T} \Sigma^{-1} \mu+\lambda^{T} \Sigma^{-1} e}, \\
& \lambda=\frac{-B+\sqrt{B^{2}-4 A C}}{2 A}
\end{aligned}
$$

di mana $A=e^{T} \Sigma^{-1} e, B=(2 \tau+1)\left(\mu \Sigma^{-1} e+e^{T} \Sigma^{-1} \mu\right)$, dan $C=(2 \tau+1) \mu^{T} \Sigma^{-1} \mu-z_{\alpha}^{2}$.

\subsection{Pemilihan Model Terbaik}

Untuk menghasilkan model yang dapat mewakili data, terlebih dahulu harus memilih model terbaik dari kandidat model yang tersedia. Ada beberapa kriteria pemilihan model, salah satunya adalah Akaike's Information Criterion (AIC). 
Persamaan AIC adalah sebagai berikut [2]:

$$
A I C=e^{2 k / n} \frac{\Sigma \widehat{u_{t}^{2}}}{n}=e^{2 k / n} \frac{R S S}{n} .
$$

Model terbaik adalah model yang memiliki nilai AIC terkecil.

\subsection{Uji Asumsi Residual}

Sebelum melakukan peramalan, model terbaik yang diperoleh didiagnosa apakah telah layak digunakan untuk peramalan dengan melakukan uji terhadap residual model. Model dikatakan layak digunakan bila residual model tidak mengandung autokorelasi, berdistribusi normal, dan tidak heteroskedastisitas. Untuk melihat apakah residual tidak mengandung autokorelasi dapat dilakukan dengan menggunakan uji L-Jung Box, normalitas residual dapat dilihat dengan melakukan uji Jarque Berra, dan heteroskedastisitas pada residual dapat dilihat dengan uji white [2].

\section{Pembahasan}

\subsection{Estimasi Model Rata-rata}

Data yang digunakan adalah nilai return saham dari lima perusahaan yaitu PT Astra Internasional, PT Bank Central Asia, PT Bank Negara Indonesia, PT Bank Rakyat Indonesia, PT Telekmunikasi Indonesia dengan periode mingguan dari tanggal 3 Januari 2010 sampai 31 Desember 2017 yang berjumlah 417 data.

Tahap awal yang dilakukan adalah memplot data return setiap perusahaan. Berdasarkan plot data terlihat bahwa nilai return sudah stasioner. Selanjutnya mengidentifikasi model ARMA dengan melihat korelogram. Korelogram ACF dan PACf dari data return menunjukkan koefisien yang berada di luar batas adalah pada lag-1 dan lag-1 untuk setiap perusahaan. Sehingga model ARMA(p,q) dengan orde p dan q yang memungkinkan yaitu 1. Dengan demikian kombinasi model yang bisa dibentuk adalah $\operatorname{ARMA}(1,0), \operatorname{ARMA}(0,1)$, dan $\operatorname{ARMA}(1,1)$.

Berdasarkan kombinasi model yang dibentuk akan dipilih model terbaik berdasarkan nilai AIC terkecil. Nilai AIC terkecil diperoleh pada model ARMA $(0,1)$ untuk PT Astra Internasional, ARMA(1,0) untuk PT Bank Central Asia, ARMA $(1,1)$ untuk PT Bank Negara Indonesia, ARMA $(0,1)$ untuk PT Bank Rakyat Indonesia, dan ARMA $(0,1)$ untuk PT Telekomunikasi Indonesia. Sehingga modelmodel tersebut adalah model terbaik diantara kandidat model yang diperoleh. Pada Tabel 1 diberikan model dari masing-masing perusahaan.

Setelah diperoleh model terbaik, dilakukan uji asumsi residual untuk melihat apakah model terbaik yang diperoleh layak digunakan untuk peramalan. Model dikatakan layak digunakan jika residual tidak megandung autokorelasi, berdistribusi normal, dan tidak terdapat efek heteroskedastisitas.

Berdasarkan uji asumsi residual yang telah dilakukan, disimpulkan bahwa model return untuk perusahaan BBCA dan BBNI mengandung efek heteroskedastisitas. Namun secara keseluruhan model tidak mengandung autokorelasi dan tidak berdistribusi normal. Hal ini sering terjadi untuk kasus data ekonomi terutama harga sa- 
Tabel 1. Model Return Terbaik untuk Setiap Perusahaan

\begin{tabular}{|c|c|c|}
\hline No & Perusahaan & Model Terbaik \\
\hline 1 & ASII & $X_{t}=0.2553392 \epsilon_{t-1}+\epsilon_{t}$ \\
\hline 2 & BBCA & $X_{t}=-0.166422 X_{t-1}+\epsilon_{t}$ \\
\hline 3 & BBNI & $X_{t}=-0.799388 X_{t-1}+0.710914 \epsilon_{t-1}+\epsilon_{t}$ \\
\hline 4 & BBRI & $X_{t}=0.105222 \epsilon_{t-1}+\epsilon_{t}$ \\
\hline 5 & TLKM & $X_{t}=-0.213582 \epsilon_{t-1}+\epsilon_{t}$ \\
\hline
\end{tabular}

Tabel 2. Model Volatilitas Terbaik untuk Setiap Perusahaan

\begin{tabular}{|c|c|c|}
\hline No & Perusahaan & Model Terbaik \\
\hline 1 & ASII & $\sigma_{t}^{2}=0.000848+0.220579 \epsilon_{t-1}^{2}+0.338066 \sigma_{t-1}^{2}$ \\
\hline 2 & BBCA & $\sigma_{t}^{2}=0.0000741+0.090614 \epsilon_{t-1}^{2}+0.836558 \sigma_{t-1}^{2}$ \\
\hline 3 & BBNI & $\sigma_{t}^{2}=0.000134+0.085247 \epsilon_{t-1}^{2}+0.856245 \sigma_{t-1}^{2}$ \\
\hline 4 & BBRI & $\sigma_{t}^{2}=0.001605-0.034209 \epsilon_{t-1}^{2}+0.116749 \sigma_{t-1}^{2}$ \\
\hline 5 & TLKM & $\sigma_{t}^{2}=0.0000719+0.039916 \epsilon_{t-1}^{2}+0.893363 \sigma_{t-1}^{2}$ \\
\hline
\end{tabular}

ham dikarenakan pergerakan harga saham yang berfluktuasi sehingga asumsi kenormalan dapat diabaikan.

\subsection{Estimasi Model Volatilitas}

Dalam pemodelan volatilitas akan digunakan data residual kuadrat dari model ratarata yang telah diestimasi sebelumnya. Model yang akan digunakan adalah model GARCH. Dalam penelitian ini model yang akan diduga hanya model $\operatorname{GARCH}(1,1)$, $\operatorname{GARCH}(1,2)$, dan $\operatorname{GARCH}(2,1)$ karena model-model tersebut biasanya sudah cukup baik untuk memodelkan volatilitas data. Dari ketiga model tersebut akan dipilih salah satu model terbaik. Model terbaik didapatkan dari model yang memiliki nilai AIC terkecil. Sehingga model terbaik diantara ketiga model tersebut untuk masing-masing perusahaan adalah model $\operatorname{GARCH}(1,1)$ yang disajikan pada Tabel 2 .

Setelah diperoleh model volatilitas terbaik untuk masing-masing perusahaan, selanjutnya akan dilakukan uji asumsi terhadap sisaan kuadrat dari setiap model yang terpilih.

Berdasarkan uji asumsi residual yang telah dilakukan, disimpulkan bahwa model volatilitas untuk setiap perusahaan tidak mengandung autokorelasi, tidak terdapat efek heteroskedastisitas, dan tidak berdistribusi normal. Data harga saham memiliki fluktuasi yang tinggi, karena itu sangat sering dijumpai bahwa data tidak berdistribusi normal, maka dari itu pada kasus ini asumsi kenormalan dapat diabaikan.

Setelah melakukan langkah-langkah estimasi model volatilitas di atas, dapat diyakini bahwa model Volatilitas pada Tabel 2 adalah model yang sesuai. Sehingga model return berubah menjadi pada Tabel 3 . 
Tabel 3. Model Return Terbaik untuk Setiap Perusahaan

\begin{tabular}{|c|c|c|}
\hline No & Perusahaan & Model Terbaik \\
\hline 1 & ASII & $X_{t}=0.2517732 \epsilon_{t-1}+\epsilon_{t}$ \\
\hline 2 & BBCA & $X_{t}=-0.141950 X_{t-1}+\epsilon_{t}$ \\
\hline 3 & BBNI & $X_{t}=-0.854393 X_{t-1}+0.7794489 \epsilon_{t-1}+\epsilon_{t}$ \\
\hline 4 & BBRI & $X_{t}=0.100036 \epsilon_{t-1}+\epsilon_{t}$ \\
\hline 5 & TLKM & $X_{t}=-0195856 \epsilon_{t-1}+\epsilon_{t}$ \\
\hline
\end{tabular}

\subsection{Peramalan Nilai Return dan Varian}

Setelah diperoleh model ARMA dan GARCH terbaik, selanjutnya akan dilakukan peramalan. Peramalan dilakukan untuk 5 (lima) minggu berikutnya yaitu tanggal 1 Januari 2018 sampai 29 Januari 2018. Berdasarkan Tabel 2 dan 3 diperoleh peramalan return dan varian untuk lima minggu berikutnya dengan menggunakan software Eviews 8.0 disajikan pada Tabel 4.

Tabel 4. Nilai Ramalan Return Saham, Varian, dan Volatilitasuntuk Setiap Perusahaan

\begin{tabular}{|c|c|c|c|c|c|c|}
\hline Tanggal & Ramalan & ASII & BBCA & BBNI & BBRI & TLKM \\
\hline \multirow{3}{*}{ 1-Jan-18 } & Return & -0.00063 & 0 & -0.0025 & -0.0003 & -0.0014 \\
\cline { 2 - 7 } & Varian & 0.0013 & 0.00068 & 0.00179 & 0.00132 & 0.0009 \\
\cline { 2 - 7 } & Volatilitas & 0.03602 & 0.02598 & 0.04240 & 0.03637 & 0.02998 \\
\hline \multirow{3}{*}{ 8-Jan-18 } & Return & 0 & 0 & 0.0020 & 0 & 0 \\
\cline { 2 - 7 } & Varian & 0.00157 & 0.0007 & 0.00182 & 0.00136 & 0.00091 \\
\cline { 2 - 7 } 15-Jan-18 & Volatilitas & 0.03966 & 0.02645 & 0.04274 & 0.03693 & 0.03018 \\
\hline & Return & 0 & 0 & -0.0017 & 0 & 0 \\
\cline { 2 - 7 } & Varian & 0.00173 & 0.00072 & 0.00185 & 0.0014 & 0.00092 \\
\cline { 2 - 7 } 22-Jan-18 & Volatilitas & 0.04155 & 0.02688 & 0.04305 & 0.03018 & 0.03036 \\
\cline { 2 - 7 } & Return & 0 & 0 & 0.0015 & 0 & 0 \\
\cline { 2 - 7 } & Varian & 0.00181 & 0.00074 & 0.00187 & 0.00144 & 0.00093 \\
\hline \multirow{3}{*}{ 29-Jan-18 } & Return & 0.04257 & 0.02727 & 0.04334 & 0.03788 & 0.03052 \\
\cline { 2 - 7 } & Varian & 0.00186 & 0.00076 & 0.00190 & 0.00147 & 0.00094 \\
\cline { 2 - 7 } & Volatilitas & 0.04313 & 0.02764 & 0.04362 & 0.03830 & 0.03069 \\
\hline
\end{tabular}

Berdasarkan Tabel 4 terlihat bahwa nilai ramalan return 5 periode kedepan mengalami fluktuasi, sementara nilai volatilitasnya semakin naik. Pada saat nilai ramalan return bernilai negatif, ini menunjukkan harga penutupan saham mengalami penurunan dari periode sebelumnya. Demikian juga sebaliknya, saat nilai ramalan return bernilai positif artinya harga penutupan saham mengalami kenaikan dari periode sebelumnya.

\subsection{Pembentukan Portofolio}

Dengan menggunakan perhitungan bobot portofolio dapat diketahui bahwa investor akan berinvestasi dengan bobot $5.47 \%$ untuk saham PT Astra Internasional Tbk, 44.52\% untuk saham PT Bank Central Asia Tbk, 1.49\% untuk saham PT Bank 
Negara Indonesia Tbk, $6.48 \%$ untuk saham PT Bank Rakyat Indonesia Tbk, dan 42.02\% untuk saham PT Telekomunikasi Indonesia Tbk. Ini menunjukkan bahwa bobot tertinggi dimiliki oleh saham PT Bank Central Asia.

Dalam menghitung nilai VaR digunakan hasil peramalan nilai volatilitas yang sudah diperoleh pada Tabel 2 dan 3. Diberikan investasi awal sebesar Rp. 1000.000.000,00, diperoleh nilai VaR untuk masing-masing perusahaan yang disajikan pada Tabel 5 .

Tabel 5. Hasil Perhitungan Nilai VaR 5 Periode Berikutnya pada Setia Perusahaan

\begin{tabular}{|c|c|c|c|c|c|}
\hline P & ASII & BBCA & BBNI & BBRI & TLKM \\
\hline 1 & $59,265,676$ & $42,738,354$ & $69,751,290$ & $59,833,695$ & $49,322,576$ \\
\hline 2 & $65,242,450$ & $43,522,609$ & $70,312,235$ & $60,753,750$ & $49,650,667$ \\
\hline 3 & $68,361,576$ & $44,231,845$ & $70,830,410$ & $61,572,242$ & $49,949,525$ \\
\hline 4 & $70,043,010$ & $44,869,618$ & $71,305,815$ & $62,314,893$ & $50,219,670$ \\
\hline 5 & $70,964,163$ & $45,468,705$ & $71,759,835$ & $63,005,862$ & $50,488,370$ \\
\hline
\end{tabular}

Pada Tabel 5 dapat dilihat perhitungan nilai VaR untuk masing-masing perusahaan. Misalkan untuk saham BBNI pada tingkat kepercayaan $95 \%$ pada periode 01 Januari 2018, jika seorang investor menginvestasikan dananya sebesar Rp.1.000.000.000,00 kerugian maksimum yang akan diperolehnya adalah sebesar Rp. 69,751,290. Perhitungan nilai VaR ini dapat membantu investor untuk mempertimbangkan apakah akan berinvestasi atau tidak di perusahaan tersebut.

\section{Kesimpulan}

Dari hasil pembahasan mengenai pengukuran nilai Value at Risk menggunakan model ARMA-GARCH pada saham sektor perbankan dengan periode yang sama yaitu 3 Januari 2010 sampai 31 Desember 2017 diperoleh beberapa kesimpulan, yaitu:

(1) Dari perhitungan bobot portofolio diperoleh pembagian sebagai berikut, $5.47 \%$ untuk saham PT Astra Internasional Tbk, $44.52 \%$ untuk saham PT Bank Central Asia Tbk, 1.49\% untuk saham PT Bank Negeri Indonesia, 6.48\% untuk saham PT Bank Rakyat Indonesia Tbk, dan $42.02 \%$ untuk saham PT Telekomunikasi Indonesia Tbk.

(2) Diperoleh nilai VaR terbesar sampai terkecil secara berturut-turut terjadi pada saham PT Bank Negara Indonesia Tbk, PT Astra Internasional Tbk, PT Bank Rakyat Indonesia Tbk, PT Telekomunikasi Indonesia Tbk, dan PT Bank Central Asia Tbk.

\section{Daftar Pustaka}

[1] Fuad, R. N., 2012,Optimasi Fortofolio Mean-VaR dalam Bentuk Valuta Asing, Tesis di Universitas Andalas, tidak diterbitkan

[2] Gujarati, D. N., Dawn, C. P., 2009,Basic Econometrics, Edisi ke-5, McGrawHill, New York 
8 Adellara Mutya $R$ dkk

[3] Jorion, P., 2007, Value at Risk: The Benchmark for Managing FinancialRisk, Edisi ke-3, The McGraw-Hill, New York

[4] Tandelin. E., 2010, Portofolio dan Investasi, Edisi ke-1, Kanisius, Yogyakarta

[5] Tsay, R. S., 2002, Analysis of Financial Time Series: Financial Econometrics, John Wiley \& Sons, Canada 